\title{
Salt partition, ion equilibria, and the structure, composition, and solubility of micellar calcium phosphate in bovine milk with added calcium salts
}

\author{
Qian Wang, ${ }^{1,2} \oplus$ Carl Holt, ${ }^{3} \odot$ Tommy Nylander, $^{2} \oplus$ and Ying $\mathrm{Ma}^{1 *} \oplus$ \\ ${ }^{1}$ School of Chemistry and Chemical Engineering, Harbin Institute of Technology, 92 Xidazhi Street, Nangang District, Harbin 150001, China \\ ${ }^{2}$ Department of Chemistry, Division of Physical Chemistry, Lund University, PO Box 124, SE-221 00 Lund, Sweden \\ ${ }^{3}$ Institute of Molecular, Cell and Systems Biology, University of Glasgow, Glasgow G12 8QQ, UK
}

\begin{abstract}
Increasing dietary calcium has been suggested to have a range of health benefits, such as reducing the risk of osteoporosis and hypertension. However, producing calcium-fortified products is challenging due to the destabilizing effect caused by added calcium. We provide new data on the effect of adding either calcium gluconate or calcium lactate at up to $50 \mathrm{~m} M$ on the partition of salts and the structure and solubility of micellar calcium phosphate (MCP). The empirical chemical formula of the MCP in milk with added calcium was $\mathrm{Ca}\left(\mathrm{HPO}_{4}\right)_{0.6}\left(\mathrm{PO}_{4}\right)_{0.267}$, similar to that previously reported for the MCP in native bovine casein micelles. Ion equilibria calculations showed that the solubility of the MCP was decreased as measured by an increase in negative logarithm of the solubility constant $\left(\mathrm{p} K_{S}\right)$ from 6.8 to $7.3 \pm 0.1$ and $7.5 \pm 0.1$ for milk with added calcium gluconate and calcium lactate, respectively. No substantial change in the amorphous structure of the MCP was observed by either X-ray powder diffraction or infrared spectroscopy of dried casein micelles as a result of added calcium. The conclusion is that the added calcium caused an increase in the concentration of the MCP and decreased its solubility without changing its amorphous structure or chemical composition.
\end{abstract}

Key words: milk salt partition, calcium phosphate, ion activity product, calcium addition

\section{INTRODUCTION}

It has been claimed that increasing dietary calcium contributes to reducing the risks of osteoporosis, hypertension, colon cancer, kidney stones, and lead absorption (McCarron and Heaney, 2004). Consumer demand for high-calcium products has promoted the development of calcium-fortified dairy products (Singh

Received May 3, 2020.

Accepted July 6, 2020.

*Corresponding author: maying@hit.edu.cn and Muthukumarappan, 2008). A particular advantage of dairy supplementation is the possible role of casein phosphopeptides in facilitating calcium absorption in the small intestine (Perego et al., 2015) due to the calcium-binding behavior of the phosphopeptides at alkaline condition (Luo et al., 2020). Calcium has been added to milk as different salts such as calcium carbonate, tricalcium phosphate, calcium chloride, calcium gluconate, and calcium lactate (Vavrusova and Skibsted, 2014). Calcium carbonate and tricalcium phosphate are not primary options for calcium fortification because of their low solubility in milk (Ranjan et al., 2005). Calcium chloride is easily dissolved in milk, but it causes a notable decrease in $\mathrm{pH}$ and an increase in free calcium ion $\left(\mathrm{Ca}^{2+}\right)$ concentration, which tends to reduce the stability of milk products (Sievanen et al., 2008; Tsioulpas et al., 2010). In contrast, calcium salts of gluconic and lactic acids are highly soluble and have a less destabilizing effect. The sensory properties of milk after adding either calcium gluconate or lactate, together with disodium phosphate to promote stability, did not change, and the heat stability was slightly improved (Singh et al., 2007).

The type of salt added to milk also plays an important part in maintaining the bioavailability of calcium. Simple salts such as calcium carbonate and phosphate, which are only slightly soluble in the aqueous phase of milk, are partly dissolved by stomach acid. However, the ionic calcium formed in the stomach may precipitate in the more alkaline conditions of the small intestine. This precipitation process could reduce calcium bioavailability (Vavrusova and Skibsted, 2014) but may be counteracted by casein phosphopeptides, which have been shown to resist digestion and enter the small intestine (Caira et al., 2016). In contrast, the addition of soluble salts results in increases in uptake and retention of calcium (Singh et al., 2007). Notably, Singh et al. (2007) found that the bioavailability of calcium from milk enriched with calcium gluconate or lactate was higher than that from milk enriched with calcium chloride. The use of gluconate and lactate salts 
is therefore a promising way to achieve stable dairy products with added calcium, which is further explored in the present study. Despite the advantages in terms of increased nutritional value, adding calcium to milk products is challenging in practical processing because of the complexity of salt equilibria and their effect on the casein micelle structure and stability of the product (de la Fuente, 1998). Indeed, several studies have shown that the type of calcium salt added to milk affects the salt partition differently (Gaucheron, 2005; On-Nom et al., 2010). This depends not only on the solubility and concentrations of added calcium salts but also on any needed adjustment of $\mathrm{pH}$ after the addition. Addition of 0 to $30 \mathrm{~m} M$ calcium liberates protons and thereby lowers $\mathrm{pH}$. Together with the increase in free calcium ion concentration, the stability of the milk protein is decreased (Omoarukhe et al., 2010). Reducing pH decreases the concentration of micellar calcium phosphate (MCP) due to the protonation of $\mathrm{P}_{\mathrm{i}}$, leading to structural changes in the casein micelles (GonzalezJordan et al., 2015). When the $\mathrm{pH}$ is readjusted back to the original value, the changes in salt equilibria in response to added calcium are considered to be largely reversible. For example, at $\mathrm{pH} 6.6$ or 6.0 , the addition of calcium D-lactobionate from 0 to $50 \mathrm{~m} M$ caused a significant increase in the concentrations of micellar calcium and phosphate and a decrease in supernatant phosphate (Koutina et al., 2015). With calcium added at $40 \mathrm{mM}$, almost all of the milk phosphate was found in the micelles (Arifin et al., 2014).

Although the effect of calcium addition on the salt partition has been studied, less attention has been paid to identifying the nature of the calcium phosphate formed after the addition. In bovine milk at physiological $\mathrm{pH}$, the total concentrations of calcium and phosphate are well in excess of their solubility. This is possible because approximately half the $\mathrm{P}_{\mathrm{i}}$ and twothirds of the calcium are in the micelles, mostly sequestered by caseins containing phosphate centers to form nanoclusters of an amorphous calcium phosphate. The complexes are closely similar in composition and structure to MCP isolated from milk by proteolysis (Ono et al., 1994; Lenton et al., 2016). The high calcium concentration and protein stability of milk is achieved without precipitating calcium phosphate in the mammary gland by forming such nanoclusters (Carver and Holt, 2019). The addition of calcium salts to milk alters the ion equilibria and partition of salts between casein micelles and the serum. In a typical milk, about $90 \%$ of the casein phosphate groups in phosphate centers are bound to the native calcium phosphate nanoclusters, so there is only a limited capacity to form additional complexes when calcium salts are added. The changes in MCP nanoclusters are not yet clearly understood in detail. Therefore, this study was conducted to reveal both the changes in salt partition and the structure of the MCP after the addition of calcium salts. The question to be answered was whether a separate pure phase of calcium phosphate was formed, possibly more crystalline than the amorphous nanoclusters in the native $\mathrm{MCP}$, or whether a rearrangement occurred in which the ratio of casein to calcium phosphate in the nanocluster complexes progressively decreased as the concentration of added calcium salts was increased.

For this purpose, the changes in the partition of milk salts were investigated in response to the addition of either calcium gluconate or calcium lactate, and the salt partition results were compared with a thermodynamic model of the salt partition and ion equilibria in milk (Bijl et al., 2019). Furthermore, the composition and structure of calcium phosphate formed after calcium addition were determined. The nature of the calcium phosphate was revealed by determining the ion activity product (IAP), which has proved useful for determining the stoichiometry of MCP in cow, goat, and human milk (Ormrod et al., 1982; Holt, 1993). Fouriertransform infrared spectroscopy and X-ray powder diffraction were used to provide structural information on the MCP.

\section{MATERIALS AND METHODS}

\section{Materials}

All water used in the experiments was deionized water (Milli-Q Plus, Millipore Corporation, Bedford, MA). Sodium azide, calcium lactate, calcium gluconate, sodium hydroxide $(\mathrm{NaOH})$, and trichloroacetic acid of analytical grade were purchased from Kermel Chemical Reagent Co. Ltd. (Tian jin, China).

\section{Preparation of Milk Samples}

Fresh bulk bovine milk was obtained from the local farm (Harbin, China) and skimmed by centrifugation at $3,000 \times g$ for $30 \mathrm{~min}$. To prevent bacterial growth, sodium azide $(0.02 \%$, wt $/ \mathrm{vol})$ was added to the milk samples, which were then stored at $4^{\circ} \mathrm{C}$. The milk samples were prepared by adding different amounts of the calcium salts to the skim milk to increase the total calcium concentration by $0,10,20,30,40$, or $50 \mathrm{~m} M$ using either calcium gluconate or calcium lactate salts. All samples were then stirred at $25^{\circ} \mathrm{C}$ for $2 \mathrm{~h}$, and the $\mathrm{pH}$ value of each sample was readjusted to 6.70 using $1.0 \mathrm{M}$ $\mathrm{NaOH}$. To study the effect of $\mathrm{pH}$ on the salt partition of Ca-enriched milk, additional sets of samples were 
prepared containing either $40 \mathrm{~m} M$ calcium gluconate or $40 \mathrm{~m} M$ calcium lactate. Four individual samples within each set were prepared by adjusting the $\mathrm{pH}$ to $6.1,6.3$, 6.5 , or 6.7 by titration with $1 \mathrm{M} \mathrm{NaOH}$. The dilution caused by the $\mathrm{NaOH}$ was kept constant in all samples by addition of a balancing volume of deionized water.

\section{Preparation of Milk Ultrafiltrate and Pelleted Casein Micelle Samples}

After equilibration, the milk samples were ultracentrifuged at $60,000 \times g$ for $2 \mathrm{~h}$ at $25^{\circ} \mathrm{C}$ (Sigma $3-30 \mathrm{~K}$, Darmstadt, Germany). Clear supernatant was collected carefully with a syringe from each centrifuge tube and then centrifuged again at $2,173 \times g$ at $25^{\circ} \mathrm{C}$ for $30 \mathrm{~min}$ in an Amicon-Ultra-15 centrifugal filter unit (Merck, Kenilworth, NJ) tube containing a membrane with the molecular weight cut-off of 10,000 Da. The ultrafiltered fractions are termed milk ultrafiltrates, and the pellets remaining after ultracentrifugation are termed casein micelles.

\section{Salt Analyses}

The concentrations of total and ultrafiltrate salts were determined in skim milk and their corresponding ultrafiltrate fractions. The milk and milk ultrafiltrate samples were treated with trichloroacetic acid according to the procedure of Fox et al. (1967). Briefly, $1 \mathrm{~mL}$ of $24 \%$ trichloroacetic acid was added to $2 \mathrm{~mL}$ of a 5 -fold diluted sample and the mixture was shaken for $30 \mathrm{~min}$, then diluted to either 100 or $25 \mathrm{~mL}$ for cation or anion measurements, respectively. All samples were centrifuged at $1,717 \times g$ at $25^{\circ} \mathrm{C}$ for $20 \mathrm{~min}$, and the supernatants were collected for measurement. Concentrations of $\mathrm{Ca}, \mathrm{Mg}, \mathrm{K}, \mathrm{Na}$, and inorganic phosphate $\left(\mathrm{P}_{\mathrm{i}}\right)$ were determined by inductively coupled plasma atomic emission spectrometry (Perkin-Elmer Optima 5300 DV, Waltham, MA). The additional Na introduced into the samples by the adjustment of $\mathrm{pH}$ with 1 $M \mathrm{NaOH}$ was subtracted from the total $\mathrm{Na}$ value. The $\mathrm{Cl}$ was determined by ion chromatography (ICS-2100, Thermo Fisher Scientific, Waltham, MA), and citrate was determined by the pyridine-acetic anhydride colorimetric method (White and Davies, 1963). The concentrations of salts in the ultrafiltrate were converted into concentrations in the continuous phase by multiplying by a factor 0.96 to allow for the excluded volume of co-solutes in the milk. Micellar concentrations were calculated as the difference between the total and the continuous phase values. All samples were prepared in duplicate; for each set of samples, the concentrations of milk salts were measured 3 times.

\section{IAP of Calcium Phosphate in Milk}

The chemical formula of a calcium phosphate can be written as a whole-number multiple of the empirical chemical formula. For example, the chemical formula of a tricalcium phosphate $\mathrm{Ca}_{3}\left(\mathrm{PO}_{4}\right)_{2}$ is divided by 3 to give the empirical chemical formula $\mathrm{Ca}\left(\mathrm{PO}_{4}\right)_{2 / 3}$. In the more general empirical chemical formula $\mathrm{Ca}_{1}\left(\mathrm{HPO}_{4}\right)_{y}\left(\mathrm{PO}_{4}\right)_{(2-2 y) / 3}$, the value of the variable $y=$ 0 corresponds to the basic tricalcium phosphate. If $y$ $=1$, the empirical chemical formula corresponds to an acidic dicalcium phosphate, $\mathrm{CaHPO}_{4}$. The solubility of a salt can be expressed as a product of ion activities in a solution at equilibrium with the salt. For the above general empirical chemical formula, the IAP, which at equilibrium is the solubility constant $\left(\boldsymbol{K}_{S}\right)$, is the product of ion activities with exponents given by the molar ratios in the empirical chemical formula:

$$
\mathrm{IAP}=K_{S}=\left\{\mathrm{Ca}^{2+}\right\}\left\{\mathrm{HPO}_{4}^{2-}\right\}^{y}\left\{\mathrm{PO}_{4}^{3-}\right\}^{(2-2 y) / 3} .
$$

The curly brackets identify an activity rather than a concentration. The solubility of the salt is conveniently expressed by $\mathbf{p} \boldsymbol{K}_{S}$, where $\mathrm{p} K_{S}$ is the negative logarithm to base 10 of $K_{S}$. The IAP is a constant independent of the activity values of the individual ions if there is thermodynamic equilibrium between the calcium phosphate phase and the solution. Conversely, when the chemical formula of the calcium phosphate is unknown, the parameter $y$ in Equation 1 can be treated as a variable to find a value for the IAP that is invariant in solutions of variable composition in equilibrium with the calcium phosphate salt. This method was applied to the variable composition of milk diffusates from individual cows to show that an IAP was obtained with $y$ $=0.7, \mathrm{p} K_{S}=6.8$. Thus, the empirical chemical formula for the calcium phosphate nanoclusters was determined to be $\mathrm{Ca}\left(\mathrm{HPO}_{4}\right)_{0.7}\left(\mathrm{PO}_{4}\right)_{0.2}$ (Holt, 1982).

To calculate the IAP, the concentrations of free ions and ion complexes are required. This was done using an Excel program (Microsoft Corp., Redmond, WA) that implemented the algorithm described by Holt et al. (1981). The Excel program was validated by showing that it gave essentially the same calculated concentrations of ions and ion complexes as those reported in Table 2 of Holt et al. (1981) in the standard milk diffusate. The model calculations of Holt et al. (1981) were, in turn, validated by comparison with free calcium and magnesium ion concentrations determined using a variety of experimental methods. The additional intrinsic association constants needed to determine the concentrations of the 1:1 complexes formed between 
$\mathrm{Ca}^{2+}$ and the gluconate or lactate anions were taken from Vavrusova et al. (2014). The intrinsic association constants between $\mathrm{Mg}^{2+}$ and the gluconate or lactate anions were assumed to be the same as those between $\mathrm{Mg}^{2+}$ and a monocarboxylic acid (Holt et al., 1981).

The flowchart of the ion equilibria calculations is given in Figure 1. The initial input variables were the concentrations of ultrafiltrate salts and $\mathrm{pH}$, from which ion activity coefficients and practical association constants were calculated. An iterative procedure was then applied, where assumed values of $\left[\mathrm{Ca}^{2+}\right]$ and $\left[\mathrm{Mg}^{2+}\right]$ and ionic strength were entered, and the concentrations of free ions and their complexes were calculated. The concentration of the total calcium or magnesium in the ultrafiltrate was calculated by summing all the chemical species containing these components. An adjustment was made to the estimated values of the free ions, and the cycle was repeated until the calculated value of the ultrafiltrate calcium or magnesium equaled their measured values. Then, a new ionic strength value was obtained and used in a further cycle until successive estimates of the ionic strength differed by less than $1 \%$. The output included a calculation of the IAP corresponding to various calcium phosphate salt empirical chemical formulae.

\section{Salt and Casein Partition Calculation}

The model for calculating the salt partition in milk (Model 2) was described by Bijl et al. (2019). This model calculates the extent of formation of the micellar calcium phosphate using the condition that the relevant IAP equals its equilibrium value. It also uses a model for the binding of $\mathrm{Ca}^{2+}$ and $\mathrm{Mg}^{2+}$ to caseins taking into account the sequestration of the calcium phosphate nanoclusters. The composition of the caseins in all the samples was assumed to be constant and equal to the composition of the standard milk used by Bijl et al. (2019). Initial calculations with Model 2 showed that the milk sample without added calcium lay close to the border between the zones of stability and metastability. In other words, there were only just enough phosphorylated residues on the caseins to sequester the calcium phosphate nanoclusters. Hence, the additions of calcium salts took all the samples into the zone of metastability, as shown in Figure 2. Accordingly, a modification was made to the Model 2 algorithm to calculate the partition of milk salts under conditions of metastability rather than thermodynamic equilibrium. Here, it was assumed (and subsequently verified) that the addition of the calcium salts caused the formation of a calcium phosphate salt with the same empirical chemical formula as that in the core of the equilibrium calcium phosphate nanocluster. However, the resulting metastable calcium phosphate nanocluster had a lower solubility than the equilibrium calcium phosphate nanocluster.

Thus, for $n_{\text {total }}$ moles of sequestered calcium phosphate, the free energy change in forming the metastable nanoclusters is written as

$$
n_{\text {total }} \Delta G_{S}=n_{1} \Delta G_{S, 1}+\left(n_{\text {total }}-n_{1}\right) \Delta G_{S, 2},
$$

where $n_{1}$ is the maximum number of moles of the equilibrium nanoclusters that can be formed from the available casein; $\Delta G_{S, 1}$ is the free energy of forming the equilibrium nanocluster; and $\Delta G_{S, 2}$ is an adjustable free energy parameter. The free energies are written in terms of effective solubility constants:

$$
\begin{gathered}
\Delta G_{S}=-R T \ln K_{S}, \\
\Delta G_{S, 1}=-R T \ln K_{S, 1},
\end{gathered}
$$

and

$$
\Delta G_{S, 2}=-R T \ln K_{S, 2} .
$$

where $R$ is the universal gas constant and $T$ is the absolute temperature (Kelvin). Thus, in the metastable zone, the partition of milk salts is calculated using an effective solubility constant:

$$
\mathrm{p} K_{S}=n_{1} \mathrm{p} K_{S, 1}+\left(n_{\text {total }}-n_{1}\right) \mathrm{p} K_{S, 2},
$$

where the value of $n_{1}$ is found from the concentration of sequestered nanoclusters, $\mathrm{p} K_{S, 1}$ is the negative logarithm of the solubility constant for the equilibrium calcium phosphate nanoclusters sequestered by casein, and $\mathrm{p} K_{S, 2}$ is the negative logarithm of a solubility constant for the additional calcium phosphate nanoclusters formed under nonequilibrium conditions in response to addition of the calcium salt. Equation 4 provides the means of calculating the reduction in solubility of the total calcium phosphate using a linear combination of free energy terms, but it does not mean that there are 2 different types of co-existing calcium phosphate. The salt partition calculations using Equation 4 were calculated with the Metastable Model 2 (MM2) program (Bijl et al., 2019).

\section{X-Ray Diffraction Analyses}

Pellets recovered from the centrifuged milk samples were freeze-dried and then crushed to a fine powder and 


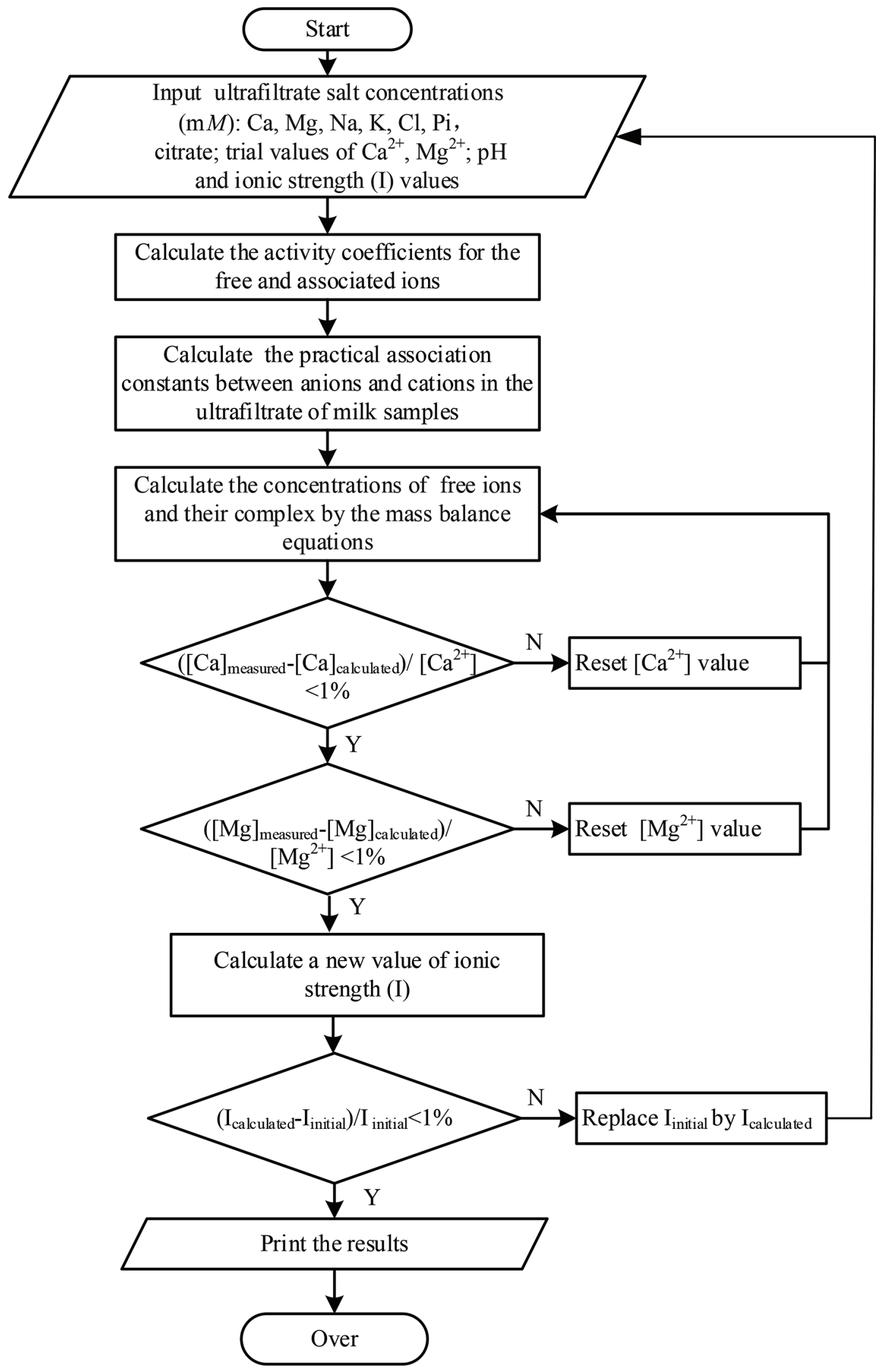

Figure 1. Flowchart of the calculation of the concentrations of free ions and their complexes in milk ultrafiltrates. $\mathrm{N}=$ no; Y $=$ yes. 
mounted in the well of the specimen holder. Powder X-ray diffraction (XRD) patterns were recorded on a Bruker D8 Advance Powder Diffractometer (Karlsruhe, Germany) using a nickel-filtered $\mathrm{Cu} \mathrm{K \alpha}$ radiation source operated at $40 \mathrm{kV}$ and $40 \mathrm{~mA}$. Diffractograms were recorded over the angular range of $10^{\circ}$ to $90^{\circ}$.

\section{Infrared Spectroscopy}

Infrared spectroscopy is a useful method of discriminating between amorphous and crystalline calcium phosphates because the crystalline order alters the shape of the vibrational and bending absorption features of the phosphate group (Holt et al., 1988, 1989). Infrared spectra were measured using a Perkin-Elmer Spectrum One Fourier transform spectrometer at 4 $\mathrm{cm}^{-1}$ resolution, averaging over 32 scans. Samples were in the form of a $\mathrm{KBr}$ disc containing $1 \%$ freeze-dried pelleted casein micelles. A pure $\mathrm{KBr}$ disc was used for baseline correction, and the intensities were normalized using the instrument's Omnic software.

\section{RESULTS AND DISCUSSION}

\section{Ion Equilibria in Calcium-Added Milk}

Table 1 shows the calculated ion species in the ultrafiltrates of the milk samples with added calcium gluconate or calcium lactate. For milk without added calcium, ultrafiltrate calcium or magnesium were mostly complexed to citrate as $\mathrm{CaCit}^{-}$or $\mathrm{MgCit}^{-}$, less was found as the free ion $\mathrm{Ca}^{2+}$ or $\mathrm{Mg}^{2+}$, and minor proportions formed weak ion pairs with chloride or protonated forms of $\mathrm{P}_{\mathrm{i}}$. Indeed, in the ultrafiltrate the $\mathrm{P}_{\mathrm{i}}$ mostly existed as the protonated forms $\mathrm{H}_{2} \mathrm{PO}_{4}{ }^{-}$and $\mathrm{HPO}_{4}{ }^{2-}$ because only small fractions were complexed with other cations. The results are comparable with other modeling results. For example, the calculated concentration of $\mathrm{Ca}^{2+}$ in this work was $2.09 \mathrm{~m} M$ compared with 2.00 $\mathrm{m} M$ (Holt et al., 1981) and $2.11 \mathrm{mM}$ (Mekmene et al., 2009). The slight differences probably arise from the different milk compositions and $\mathrm{pH}$. The model values are also comparable with an experimental value of 2.00 $\mathrm{m} M$ obtained by a selective calcium ion electrode (Lin et al., 2006).

With the addition of calcium gluconate or lactate, the concentrations of free $\mathrm{Ca}^{2+}$ and $\mathrm{Mg}^{2+}$ increased progressively, accompanied by gradual decreases in the concentrations of $\mathrm{HPO}_{4}{ }^{2-}, \mathrm{H}_{2} \mathrm{PO}_{4}^{-}, \mathrm{CaCit}^{-}$, and $\mathrm{MgCit}^{-}$(Table 1). These changes in ion concentrations are in accord with the changes in total ultrafiltrate salts after calcium addition. The finding is that the changes in individual ions and ion complexes in the ultrafiltrates reflect the transfer of salts from the serum into casein micelles. In particular, the transfer of $\mathrm{P}_{\mathrm{i}}$ indicates the formation of a calcium phosphate salt. Notably, at a given concentration of added calcium, more calcium phosphate was formed after calcium lactate addition than was formed after calcium gluconate addition. This difference may be due to either (1) the stronger affinity of calcium ions for the gluconate anion compared with the lactate anion or (2) a difference in the solubility of the calcium phosphate nanoclusters caused by incorporation of either gluconate or lactate ions in their structure.

\section{IAP of Calcium Phosphate}

The chemical composition of the micellar calcium phosphate was deduced from the value of $y$ in Equation 1 that gave an invariant IAP as a function of $\mathrm{pH}$. The $\mathrm{pH}$ variation experiments were performed on the original milk sample and on the 2 samples to which either $40 \mathrm{~m} M$ calcium lactate or $40 \mathrm{~m} M$ calcium gluconate were added. In Figure 3 the invariant IAP and IAP values calculated for the basic formula $\mathrm{Ca}\left(\mathrm{PO}_{4}\right)_{2 / 3}$ and the acidic formula $\mathrm{CaHPO}_{4}$ were obtained and plotted as a function of $\mathrm{pH}$. For the set of samples

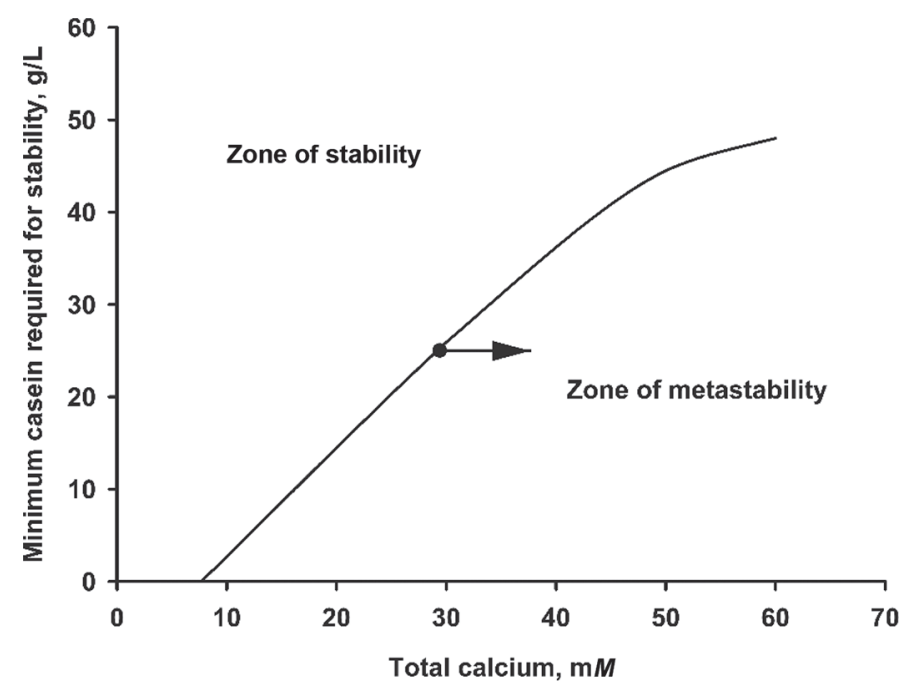

Figure 2. The minimum casein concentration required to form a thermodynamically stable solution of caseins and sequestered nanoclusters of calcium. At the boundary the fraction of sequestering highaffinity calcium binding sites is unity. The salt and total casein concentrations of the milk sample used in the present study are indicated by a filled circle. This composition lies on the stability boundary line, and calcium salt addition therefore takes the sample into the zone of metastability as indicated by the arrow. The assumed casein composition was the same as that of the standard bulk milk sample described by Bijl et al. (2019) except that the gamma caseins and their N-terminal fragments were not added to the $\beta$-casein fraction but rather allowed to participate in the ion equilibria separately. 
without added calcium (Figure 3a), the IAP values corresponding to the basic empirical chemical formula of $\mathrm{Ca}\left(\mathrm{PO}_{4}\right)_{2 / 3}$ exhibited a negative dependence on $\mathrm{pH}$. In contrast, a slight increase of IAP with $\mathrm{pH}$ was observed for the acidic chemical formula, $\mathrm{CaHPO}_{4}$. The empirical chemical formula giving the invariant IAP was $\mathrm{Ca}\left(\mathrm{HPO}_{4}\right)_{0.7}\left(\mathrm{PO}_{4}\right)_{0.2}$, and the invariant value as $\mathrm{p} K_{S}$ was $6.79 \pm 0.04$. This is in excellent agreement with previous work on individual milk samples where an invariant IAP was found for the same empirical chemical formula with the value $\mathrm{p} K_{S}=6.80$ (Holt, 1982).

The $\mathrm{pH}$ range used to determine the invariant IAP with the samples containing $40 \mathrm{~m} M$ added calcium was restricted to 6.1 to 6.7 because at higher $\mathrm{pH}$ the ultrafiltrate $\mathrm{P}_{\mathrm{i}}$ was reduced toward $0 \mathrm{~m} M$. The concentrations of ion species in the ultrafiltrates of these samples as a function of $\mathrm{pH}$, calculated as described in the Materials and Methods section, are shown in Table 2. The concentration of $\mathrm{Ca}^{2+}$ decreased from 11.01 to 8.23 and from 13.12 to $10.81 \mathrm{~m} M$ in the calcium gluconate and calcium lactate samples, respectively, as $\mathrm{pH}$ increased from 6.1 to 6.7. The concentration of $\mathrm{HPO}_{4}{ }^{2-}$ was little changed, whereas that of $\mathrm{H}_{2} \mathrm{PO}_{4}{ }^{-}$decreased and approached 0 $\mathrm{m} M$ with increasing $\mathrm{pH}$. Despite the variations in the concentrations of individual calcium and phosphate ions, an invariant value of IAP was obtained in samples with both types of added calcium salts for the slightly modified stoichiometry of $\mathrm{Ca}\left(\mathrm{HPO}_{4}\right)_{0.6}\left(\mathrm{PO}_{4}\right)_{0.267}$. The $\mathrm{p} K_{S}$ value of $\mathrm{Ca}\left(\mathrm{HPO}_{4}\right)_{0.6}\left(\mathrm{PO}_{4}\right)_{0.267}$ was 7.3 and 7.5 for the calcium gluconate and calcium lactate samples, respectively (Figure 3). The result shows that the calcium phosphate formed by added calcium was very similar in chemical composition to native MCP with the formula $\mathrm{Ca}\left(\mathrm{HPO}_{4}\right)_{0.7}\left(\mathrm{PO}_{4}\right)_{0.2}$ (Figure 3a). These findings are in substantial agreement with the work of Philippe et al. (2003), where generally smaller amounts of added calcium did not change the empirical chemical formula of the calcium phosphate. In this earlier work, ${ }^{31} \mathrm{P}$ nuclear magnetic resonance spectroscopy data showed that the added calcium caused a reduction of mobility of phosphorylated residues in the caseins. This was found to be consistent with the sequestration of the additional calcium phosphate by caseins and their incorporation in micelles. Despite the similarity in chemical composition, the solubility, in terms of the measured $K_{S}$, was 3 to 6 times smaller after adding $40 \mathrm{~m} M$ calcium. This validates the assumption of the modified model (MM2) that the solubility of the MCP decreases as the proportion of sequestering caseins is reduced (Figure 2). Equation 4 can be approximated by a linear function of the concentration of added calcium:

$$
\mathrm{p} K_{S}=\mathrm{p} K_{S, \mathrm{o}}+0.015[\mathrm{Ca}]_{\text {added }},
$$

where $\mathrm{p} K_{S, \mathrm{o}}$ is the negative $\log$ of the IAP of the equilibrium calcium phosphate nanoclusters found in most native milk and $[\mathrm{Ca}]_{\text {added }}$ is the concentration of added calcium salts (in $\mathrm{m} M$ ).

\section{Characterization of the Structure of the Calcium Phosphate}

The XRD patterns of freeze-dried casein micelle pellets of the original milk and the milk with $40 \mathrm{~m} M$ added calcium gluconate or lactate were recorded, and typical diffractograms are shown in Figure 4a. The effect of the added $40 \mathrm{~m} M$ calcium was to approximately double the concentration of MCP as judged by the changes in

Table 1. Calculated concentrations $(\mathrm{m} M)$ of some of the main free ions and ion complexes in the ultrafiltrates from milk samples containing added calcium gluconate or lactate ${ }^{1,2}$

\begin{tabular}{|c|c|c|c|c|c|c|c|}
\hline Added salt, $\mathrm{m} M$ & \multicolumn{6}{|c|}{ Ions and complexes } & $\mathrm{CaRCOO}^{+}$ \\
\hline 0 & 2.09 & 0.78 & 6.23 & 1.70 & 2.59 & 6.69 & 0.00 \\
\hline \multicolumn{8}{|l|}{ Calcium gluconate } \\
\hline 10 & 3.25 & 0.92 & 6.09 & 1.26 & 1.56 & 3.89 & 2.22 \\
\hline 20 & 4.97 & 1.14 & 5.89 & 1.00 & 0.93 & 2.23 & 6.26 \\
\hline 30 & 6.16 & 1.45 & 5.55 & 0.97 & 0.62 & 1.43 & 10.92 \\
\hline 10 & 3.39 & 0.99 & 6.14 & 1.32 & 1.47 & 3.68 & 1.36 \\
\hline 20 & 5.86 & 1.18 & 6.22 & 0.92 & 0.70 & 1.68 & 4.35 \\
\hline 30 & 9.16 & 1.52 & 5.97 & 0.74 & 0.27 & 0.62 & 9.20 \\
\hline 40 & 10.37 & 1.98 & 5.61 & 0.80 & 0.16 & 0.35 & 13.20 \\
\hline 50 & 13.23 & 2.13 & 5.43 & 0.66 & 0.08 & 0.17 & 19.67 \\
\hline
\end{tabular}

\footnotetext{
${ }^{1}$ The calculation of the ion equilibria used the Excel program (Microsoft Corp., Redmond, WA) described in the Materials and Methods section. ${ }^{2} \mathrm{CaCit}^{-}$and $\mathrm{MgCit}^{-}$are complexes of calcium and magnesium ions with the unprotonated trivalent citrate ion, respectively. $\mathrm{CaRCOO}^{+}$is a complex of calcium ion with gluconate or lactate ion.
} 
(a)

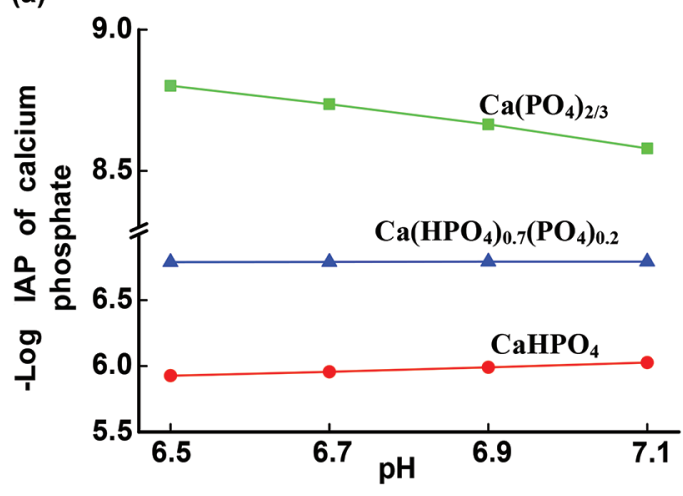

(c)

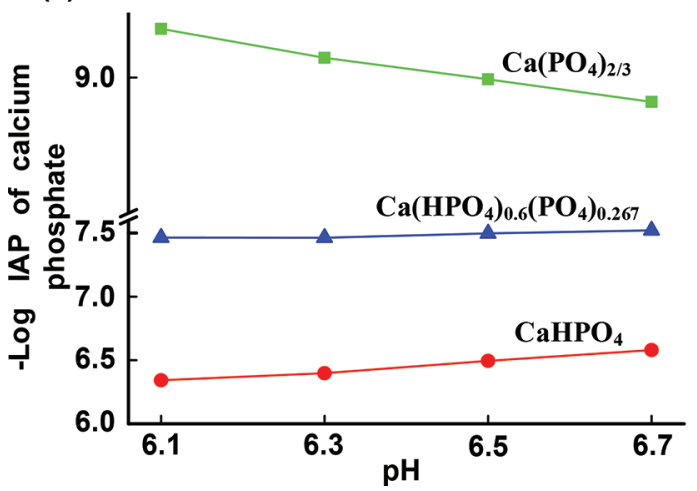

(b)

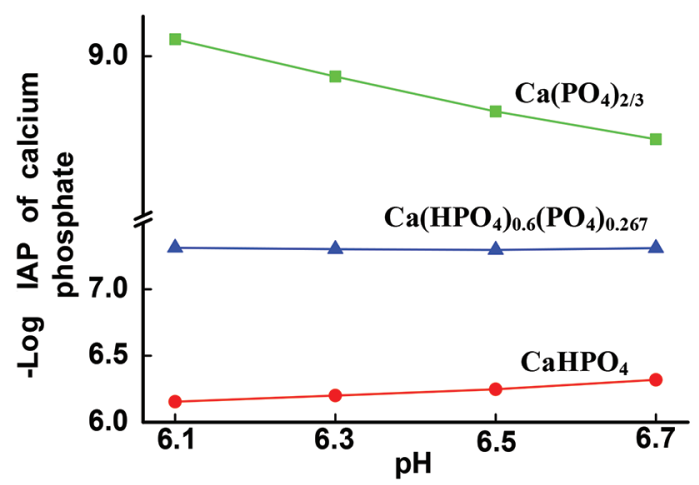

Figure 3. Invariant ionic activity (IAP) values for the basic formula $\mathrm{Ca}\left(\mathrm{PO}_{4}\right)_{2 / 3}$ and the acidic formula $\mathrm{CaHPO}$ as a function of $\mathrm{pH}$ calculated for milk without calcium addition (a), milk with $40 \mathrm{~m} M$ calcium gluconate added (b), and milk with $40 \mathrm{~m} M$ calcium lactate added (c).

ultrafiltrate $\mathrm{P}_{\mathrm{i}}$. For the sample without added calcium, a broad peak appeared near a scattering angle of $20^{\circ}$ with a low signal:noise ratio, which is characteristic of a highly disordered phase (Wang and Nancollas, 2008). No sharp diffraction peaks corresponding to crystalline calcium phosphate were seen in the diffractograms of

Table 2. Concentrations $(\mathrm{m} M)$ of some of the main free ions and ion complexes in the ultrafiltrates from the original milk and milk samples containing $40 \mathrm{~m} M$ added calcium gluconate or lactate as a function of $\mathrm{pH}^{1,2}$

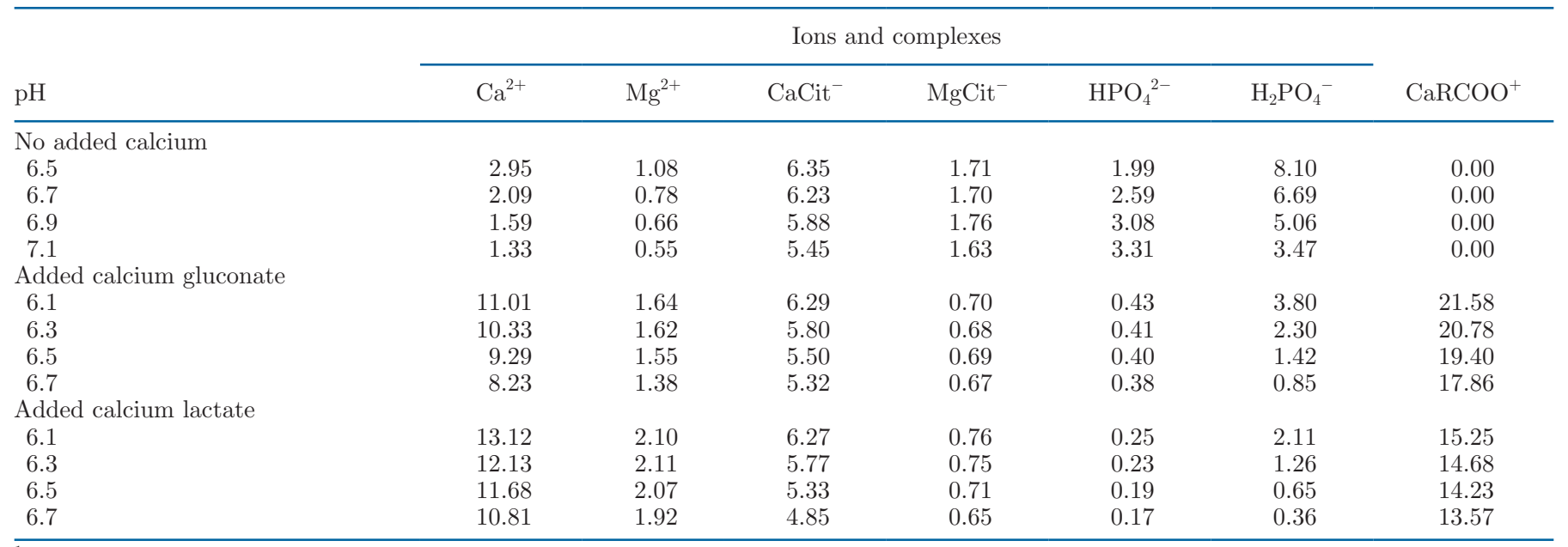

${ }^{1}$ The calculation of the ion equilibria used the Excel program (Microsoft Corp., Redmond, WA) described in the Materials and Methods section. ${ }^{2} \mathrm{CaCit}^{-}$and $\mathrm{MgCit}^{-}$are complexes of calcium and magnesium ions with the unprotonated trivalent citrate ion, respectively. $\mathrm{CaRCOO}^{+}$is a complex of calcium ion with gluconate or lactate ion. 

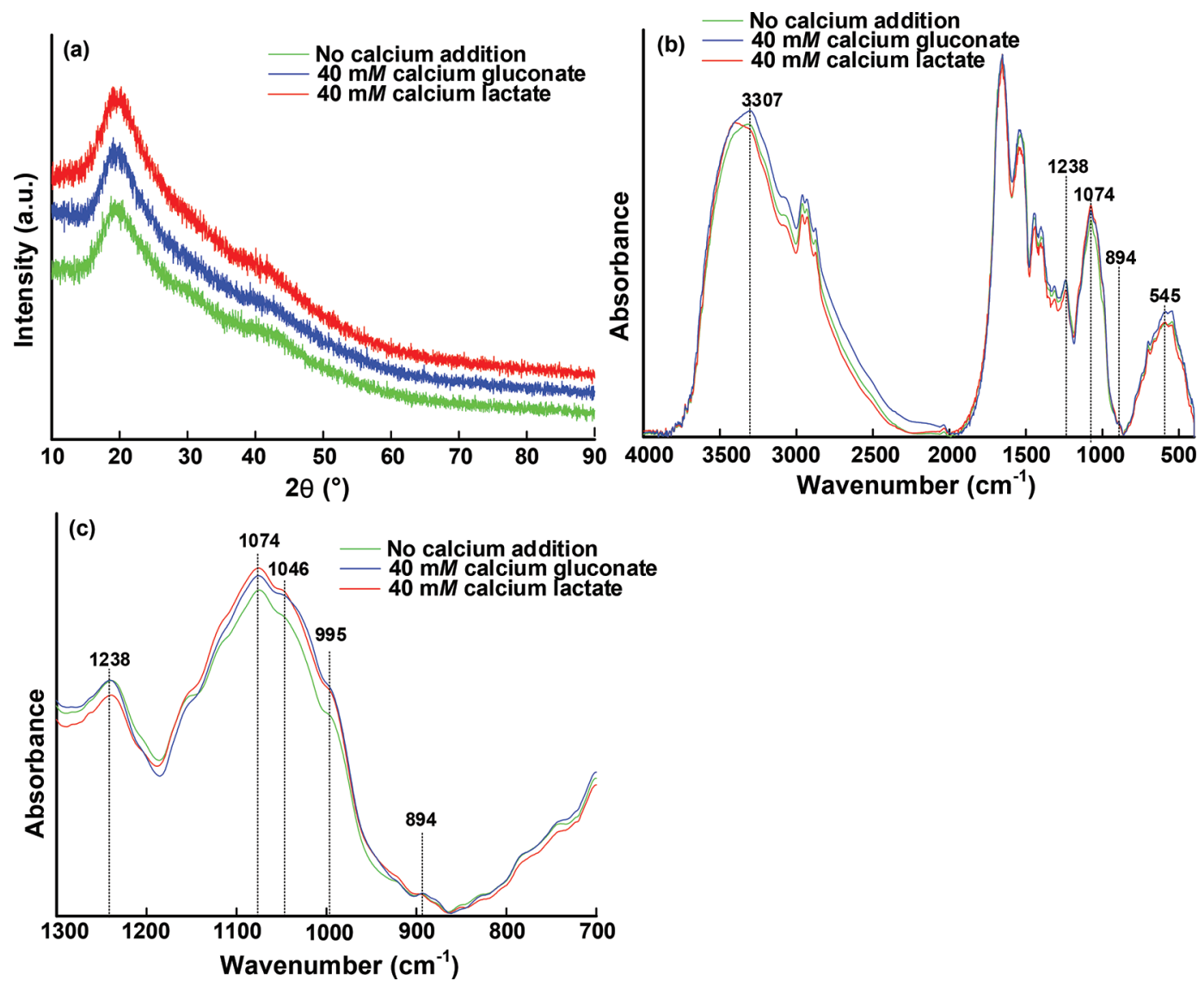

Figure 4. The amorphous nature of the micellar calcium phosphate in freeze-dried pellets of centrifuged casein micelles from milk is not affected by $40 \mathrm{~m} M$ added calcium. (a) The X-ray powder diffraction patterns. (b) Infrared spectra, where panel c shows the expanded infrared spectra of the phosphate stretching region.

samples with $40 \mathrm{~m} M$ added calcium. Because sharp diffraction peaks are easily detected against a background of amorphous scattering, the formation of a separate crystalline calcium phosphate phase can be ruled out (Harries et al., 1987; Lenton et al., 2016). This is evidence that the calcium phosphate formed in response to added calcium is likely to be as amorphous as the native calcium phosphate nanoclusters. As shown in Figure $4 \mathrm{~b}$ and c, some of the major peaks present in the infrared spectra were assigned to the internal bending and vibrational modes of water and phosphate species. A strong and broad band at about $3,300 \mathrm{~cm}^{-1}$ is expected to be the $\mathrm{OH}$ stretching mode. A well-resolved band of medium intensity at $1,238 \mathrm{~cm}^{-1}$ is due to the $\mathrm{P}-\mathrm{O}-\mathrm{H}$ bend, which may overlap the stronger amide III band of the peptide bond at $1,248 \mathrm{~cm}^{-1}$. A broad and strong feature centered at $1,074 \mathrm{~cm}^{-1}$ was assigned to the degenerate $\mathrm{O}-\mathrm{P}-\mathrm{O}$ symmetric and asymmetric stretching modes. The appearance of a lower wavenumber peak at $1,046 \mathrm{~cm}^{-1}$ possibly arose from the weak effects of site symmetry splitting that made the phos- phate stretching mode at $1,074 \mathrm{~cm}^{-1}$ appear slightly more structured. There was also a prominent shoulder at about $995 \mathrm{~cm}^{-1}$, which is likely due to the allowed symmetric stretch of the casein phosphate ester group (Figure 4c). A small band at about $890 \mathrm{~cm}^{-1}$ was assigned to the symmetric $\mathrm{P}-\mathrm{O}-(\mathrm{H})$ stretching mode. A peak of medium intensity at $545 \mathrm{~cm}^{-1}$ was assigned to the $\mathrm{O}-\mathrm{P}-\mathrm{O}$ asymmetric bending mode. In all spectra the degeneracy of the phosphate asymmetric stretch at about $1,100 \mathrm{~cm}^{-1}$ and the phosphate bending mode at about $550 \mathrm{~cm}^{-1}$ was not lifted, which would be an indication of crystalline order. Thus, the calcium phosphate formed by the added calcium is likely to be amorphous, in agreement with the finding from XRD (Figure 4a).

\section{Salt Partition in Milk with Added Calcium}

Table 3 shows that the concentration of ultrafiltrate calcium increased with the concentration of added calcium gluconate or lactate, whereas ultrafiltrate $\mathrm{P}_{\mathrm{i}}$ concentration decreased and approached $0 \mathrm{mM}$. Con- 
Table 3. Concentrations $(\mathrm{m} M)$ of salts in the ultrafiltrates of milk samples with added calcium gluconate or calcium lactate obtained experimentally ${ }^{1}$

\begin{tabular}{|c|c|c|c|c|}
\hline \multirow[b]{2}{*}{ Added salt, $\mathrm{m} M$} & \multicolumn{4}{|c|}{ Ultrafiltrate } \\
\hline & $\mathrm{Ca}$ & $\mathrm{Mg}$ & Citrate & $\begin{array}{l}\text { Inorganic } \\
\text { phosphate }\end{array}$ \\
\hline \multicolumn{5}{|l|}{ Ca-gluconate } \\
\hline 0 & $9.71 \pm 0.47^{\mathrm{a}}$ & $3.10 \pm 0.06^{\mathrm{ab}}$ & $8.26 \pm 0.08^{\mathrm{a}}$ & $11.56 \pm 0.23^{\mathrm{a}}$ \\
\hline 10 & $13.14 \pm 0.50^{\mathrm{a}}$ & $2.81 \pm 0.11^{\mathrm{a}}$ & $7.57 \pm 0.12^{\mathrm{ab}}$ & $7.02 \pm 0.16^{\mathrm{b}}$ \\
\hline 20 & $18.98 \pm 0.57^{\mathrm{b}}$ & $2.93 \pm 0.08^{\mathrm{a}}$ & $7.05 \pm 0.14^{\mathrm{ab}}$ & $4.26 \pm 0.27^{\mathrm{c}}$ \\
\hline 30 & $24.59 \pm 0.61^{\mathrm{c}}$ & $3.50 \pm 0.10^{\mathrm{b}}$ & $6.66 \pm 0.12^{\mathrm{bc}}$ & $2.85 \pm 0.24^{\mathrm{cd}}$ \\
\hline 40 & $32.36 \pm 0.51^{\mathrm{d}}$ & $3.75 \pm 0.09^{\mathrm{b}}$ & $6.40 \pm 0.13^{\mathrm{bc}}$ & $1.61 \pm 0.26^{\mathrm{d}}$ \\
\hline 50 & $42.50 \pm 0.57^{\mathrm{e}}$ & $3.71 \pm 0.11^{\mathrm{b}}$ & $6.26 \pm 0.11^{\mathrm{c}}$ & $1.16 \pm 0.17^{\mathrm{d}}$ \\
\hline \multicolumn{5}{|l|}{ Ca-lactate } \\
\hline 10 & $12.49 \pm 0.44^{\mathrm{a}}$ & $3.00 \pm 0.09^{\mathrm{a}}$ & $7.67 \pm 0.10^{\mathrm{ab}}$ & $6.68 \pm 0.17^{\mathrm{b}}$ \\
\hline 20 & $18.45 \pm 0.48^{\mathrm{b}}$ & $2.89 \pm 0.08^{\mathrm{a}}$ & $7.28 \pm 0.12^{\mathrm{ab}}$ & $3.30 \pm 0.19^{\mathrm{c}}$ \\
\hline 30 & $26.74 \pm 0.71^{\mathrm{c}}$ & $3.30 \pm 0.09^{\mathrm{b}}$ & $6.81 \pm 0.12^{\mathrm{bc}}$ & $1.32 \pm 0.17^{\mathrm{d}}$ \\
\hline 40 & $31.64 \pm 0.73^{\mathrm{c}}$ & $4.30 \pm 0.12^{\mathrm{c}}$ & $6.50 \pm 0.15^{\mathrm{bc}}$ & $0.79 \pm 0.23^{\mathrm{d}}$ \\
\hline 50 & $41.19 \pm 0.58^{\mathrm{d}}$ & $4.58 \pm 0.13^{\mathrm{c}}$ & $6.16 \pm 0.13^{\mathrm{c}}$ & $0.40 \pm 0.17^{\mathrm{d}}$ \\
\hline
\end{tabular}

${ }^{\mathrm{a}-\mathrm{e}}$ Superscripts that differ within a column and within Ca-gluconate and Ca-lactate indicate significant differences at the $5 \%$ significance level $(P<0.05)$.

${ }^{1}$ Values are means \pm SD. One-way ANOVA was used and Tukey or Dunnett's T3 analysis was used to determine statistically different groups at the $5 \%$ significance level $(P<0.05)$.

comitantly, a small increase in ultrafiltrate magnesium and a small decrease in ultrafiltrate citrate were also observed. The concentration of $\mathrm{P}_{\mathrm{i}}$ in the pellets almost doubled at the highest level of calcium salt addition. The salt partition calculated by the MM2 program was in good agreement with these experimental results, as shown in Figure 5.

The main discrepancy between the MM2 calculations and experiment is in the overestimation of ultrafiltrate calcium concentration and underestimation of ultrafiltrate magnesium at the 3 higher levels of calcium gluconate and the 2 higher levels of calcium lactate addition. In these samples the free calcium ion concentration is higher than the range of free calcium ion concentrations used to model the binding of free calcium ions to casein. Moreover, the model assumes that the binding constants of calcium and magnesium for sites on the caseins are always the same, and this may not be correct. These model assumptions may partly explain why the model overpredicts the concentration of ultrafiltrate calcium and underpredicts the concentration of ultrafiltrate magnesium. A second factor is that the formulae used to calculate activity coefficients become less accurate as the ionic strength increases, particularly above about 0.15 , and more particularly for multivalent ions. At the highest level of calcium salt added the ionic strength is about 0.14. The correlation coefficients of experimental versus calculated ultrafiltrate salt concentrations are given in the legend to Figure 5, and are all high and positive. The lowest ones are for magnesium, where the range of variation is small. Here, the model does not correctly predict the small rise in ultrafiltrate magnesium at the highest levels of added calcium gluconate or lactate.

Notwithstanding these differences, it is clear that calcium phosphate is formed by the addition of either calcium gluconate or lactate and is pelleted with the casein micelles but does not form a separate crystalline phase. Amorphous calcium phosphate spontaneously matures into poorly crystalline or highly crystalline forms in the absence of inhibitors such as phosphoproteins, and in the presence of phosphoproteins it readily forms complexes with a lower free energy (Wang and Nancollas, 2009). Thus, according to our model, it is incorporated into the calcium phosphate nanoclusters. But after sequestration, the solubility of the amorphous calcium phosphate as a whole is reduced, as measured by the IAP in the milk serum. We emphasize that the model does not propose that there are 2 types of calcium phosphate either inside or outside the micelles. It should be emphasized that the particular milk sample used was destabilized by even the smallest calcium salt addition of $10 \mathrm{~m} M$. In some other milk samples that have been examined in sufficient detail, a proportion of free caseins remains to sequester additional calcium phosphate so that the normal equilibrium complexes can form (Bijl et al., 2019).

This study demonstrated that the addition of calcium gluconate or lactate influenced the partition of milk salts, especially the calcium and phosphate equilibria. In response to 10 to $50 \mathrm{~m} M$ added calcium, ultrafiltrate $\mathrm{P}_{\mathrm{i}}$ concentration progressively decreased and approached $0 \mathrm{~m} M$, indicating the formation of additional calcium phosphate. The calculated stability diagram of 

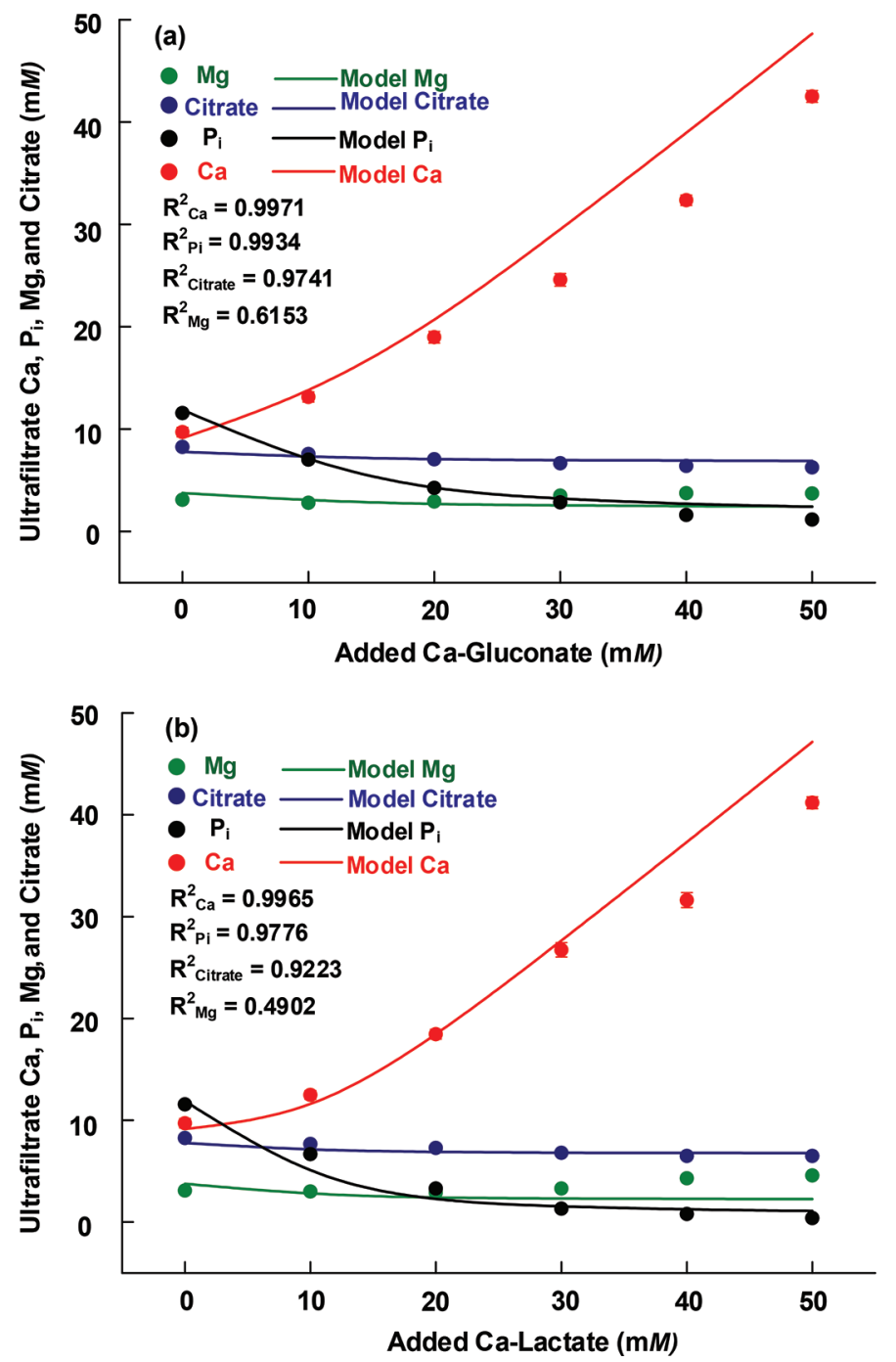

Figure 5. The ultrafiltrate concentrations of milk salts following the addition of either calcium gluconate (a) or calcium lactate (b). Experimental values are data points and the solid lines are calculated from Equation 3 with $\mathrm{p} K_{S, 2}=7.3$, where $\mathrm{p} K_{S, 2}$ is the negative logarithm of a solubility constant for the additional calcium phosphate nanoclusters formed under nonequilibrium conditions in response to addition of the calcium salt. $\mathrm{P}_{\mathrm{i}}=$ inorganic phosphate. The error bars are from the replicate measurements (i.e., the standard deviation in Table 3). The correlation coefficients $\mathrm{R}^{2}$ (experimental vs. calculated) are included in the legend.

the selected milk sample showed that the composition is on the border line between the zones of stability and metastability (Figure 2). Thus, with even the smallest addition of $10 \mathrm{~m} M$ calcium salt, the available free casein was not enough to sequester the newly formed calcium phosphate with the same stoichiometry as in native MCP. As a consequence, the thermodynamically stable MCP nanoclusters were converted to less stable complexes of calcium phosphate and caseins. It is pos- sible that the destabilized milk samples will transform over time or after heat treatment into a more thermodynamically stable state in which there is a separate pure phase of calcium phosphate with, possibly, a more crystalline structure. This did not happen in this study, indicating that the metastable complexes have a large degree of kinetic stability even if they are not thermodynamically stable. This degree of kinetic stability is consistent with the powerful influence of phosphoproteins, in general, and multiply-phosphorylated proteins in particular on the maturation of amorphous calcium phosphate. Calcium phosphate precipitation from solution is therefore strongly affected in several ways. This includes the rates of nucleation and growth of an initially amorphous phase and its subsequent maturation into a more stable and crystalline phase (Wang and Nancollas, 2009). Caseins, for example, are highly effective inhibitors of calcium phosphate precipitation and maturation at concentrations 3 orders of magnitude lower than those found in cow milk (Van Kemenade and de Bruyn, 1989a,b).

\section{CONCLUSIONS}

The invariant IAP showed that the additional calcium phosphate formed in the samples in response to the addition of calcium salts had the same empirical chemical formula as the native MCP. Moreover, diffraction and spectroscopic results showed that it was also amorphous, like the native MCP. The most likely explanation is that the calcium phosphate nanoclusters that are the core structures in MCP simply expand to accommodate the extra calcium phosphate. A rough calculation is that doubling the core mass of a calcium phosphate nanocluster with all other factors remaining constant, the core radius will increase by a factor of $2^{1 / 3}=1.26$, which might be detectable experimentally by scattering or imaging methods (De Kruif, 2014; Ingham et al., 2015, 2016; Kamigaki et al., 2018; Hettiarachchi et al., 2020). The salt partition calculations that assume thermodynamic equilibrium were therefore modified to deal with the formation of a metastable calcium phosphate by assuming that there was still an effective solubility product governing the formation of the calcium phosphate. The correlation between the calculated salt partition and the experimental results showed that the effective solubility product decreased with the concentration of calcium phosphate. The findings presented in this study contribute to a better understanding of the fundamental behavior of milk salts, especially of calcium and phosphate, during the manufacture of dairy products with added calcium. 


\section{ACKNOWLEDGMENTS}

We thank China Scholarship Council (no. 201906120367, Beijing) for providing financial support. The authors have no conflicts of interest.

\section{REFERENCES}

Arifin, M., P. J. Swedlund, Y. Hemar, and I. R. McKinnon. 2014. Calcium phosphates in $\mathrm{Ca}(2+)$-fortified milk: Phase identification and quantification by Raman spectroscopy. J. Agric. Food Chem. 62:12223-12228. https://doi.org/10.1021/jf503602n.

Bijl, E., T. Huppertz, H. val Valenberg, and C. Holt. 2019. A quantitative model of the bovine casein micelle: Ion equilibria and calcium phosphate sequestration by individual caseins in bovine milk. Eur. Biophys. J. 48:45-59. https://doi.org/10.1007/s00249-018-1330-2.

Caira, S., G. Pinto, P. Vitaglione, F. Dal Piaz, P. Ferranti, and F. Addeo. 2016. Identification of casein peptides in plasma of subjects after a cheese-enriched diet. Int. Food Res. J. 84:108-112. https:// doi.org/10.1016/j.foodres.2016.03.023.

Carver, J. A., and C. Holt. 2019. Functional and dysfunctional folding, association and aggregation of caseins. Pages 163-216 in Advances in Protein Chemistry and Structural Biology. Vol. 118. R. Donev, ed. Academic Press, Amsterdam, the Netherlands.

De Kruif, C. G. 2014. The structure of casein micelles: A review of small-angle scattering data. J. Appl. Cryst. 47:1479-1489. https:/ /doi.org/10.1107/S1600576714014563.

de la Fuente, M. A. 1998. Changes in the mineral balance of milk submitted to technological treatments. Trends Food Sci. Technol. 9:281-288. https://doi.org/10.1016/S0924-2244(98)00052-1.

Fox, K. K., V. H. Holsinger, L. P. Posati, and M. J. Pallansch. 1967. Separation of $\beta$-lactoglobulin from other milk serum proteins by trichloroacetic acid. J. Dairy Sci. 50:1363-1367. https://doi.org/10 .3168/jds.S0022-0302(67)87636-7.

Gaucheron, F. 2005. The minerals of milk. Reprod. Nutr. Dev. 45:473483. https://doi.org/10.1051/rnd:2005030.

Gonzalez-Jordan, A., P. Thomar, T. Nicolai, and J. Dittmer. 2015. The effect of $\mathrm{pH}$ on the structure and phosphate mobility of casein micelles in aqueous solution. Food Hydrocoll. 51:88-94. https:// doi.org/10.1016/j.foodhyd.2015.04.024.

Harries, J. E., D. W. L. Hukins, C. Holt, and S. S. Hasnain. 1987. Conversion of amorphous calcium phosphate into hydroxyapatite investigated by EXAFS spectroscopy. J. Cryst. Growth 84:563-570. https://doi.org/10.1016/0022-0248(87)90046-7.

Hettiarachchi, C. A., M. T. Swulius, and F. M. Harte. 2020. Assessing constituent volumes and morphology of bovine casein micelles using cryo-electron tomography. J. Dairy Sci. 103:3971-3979. https:/ /doi.org/10.3168/jds.2019-17016.

Holt, C. 1982. Inorganic constituents of milk III. The colloidal calcium phosphate of cow's milk. J. Dairy Res. 49:29-38. https://doi.org/ 10.1017/S002202990002210X.

Holt, C. 1993. Interrelationships of the concentrations of some ionic constituents of human milk and comparison with cow and goat milks. Comp. Biochem. Physiol. Comp. Physiol. 104:35-41. https: //doi.org/10.1016/0300-9629(93)90005-o.

Holt, C., D. G. Dalgleish, and R. Jenness. 1981. Calculation of the ion equilibria in milk diffusate and comparison with experiment. Anal. Biochem. 113:154-163. https://doi.org/10.1016/0003 $-2697(81) 90059-2$.

Holt, C., M. J. J. M. van Kemenade, J. E. Harries, L. S. Nelson, R. T. Bailey, D. W. L. Hukins, S. S. Hasnain, and P. L. de Bruyn. 1988. Preparation of amorphous calcium-magnesium phosphates at $\mathrm{pH}$ 7 and characterization by X-ray absorption and Fourier transform infrared spectroscopy. J. Cryst. Growth 92:239-252. https://doi .org/10.1016/0022-0248(88)90455-1.

Holt, C., M. J. J. M. Van Kemenade, L. S. Nelson Jr., D. W. L. Hukins, R. T. Bailey, J. E. Harries, S. S. Hasnain, and P. L. Debruyn. 1989. Amorphous calcium phosphates prepared at $\mathrm{pH} 6.5$ and 6.0. Mater. Res. Bull. 24:55-62. https://doi.org/10.1016/0025 -5408(89)90008-1.

Ingham, B., G. D. Erlangga, A. Smialowska, N. M. Kirby, C. Wang, L. Matia-Merino, R. G. Haverkamp, and A. J. Carr. 2015. Solving the mystery of the internal structure of casein micelles. Soft Matter 11:2723-2725. https://doi.org/10.1039/C5SM00153F.

Ingham, B., A. Smialowska, G. D. Erlangga, L. Matia-Merino, N. M. Kirby, C. Wang, R. G. Haverkamp, and A. G. Carr. 2016. Revisiting the interpretation of casein micelle SAXS data. Soft Matter 12:6937-6953. https://doi.org/10.1039/C6SM01091A.

Kamigaki, T., Y. Ito, Y. Nishino, and A. Miyazawa. 2018. Microstructural observation of casein micelles in milk by cryo-electron microscopy of vitreous sections (CEMOVIS). Microscopy (Oxf.) 67:164-170. https://doi.org/10.1093/jmicro/dfy012.

Koutina, G., J. C. Knudsen, and L. H. Skibsted. 2015. The effect of $\mathrm{pH}$ on calcium and phosphorus distribution between micellar and serum phase after enrichment of skim milk with calcium D-lactobionate. Dairy Sci. Technol. 95:63-74. https://doi.org/10.1007/ s13594-014-0196-z.

Lenton, S., T. Nylander, C. Holt, L. Sawyer, M. Härtlein, H. Müller, and S. C. M. Teixeira. 2016. Structural studies of hydrated samples of amorphous calcium phosphate and phosphoprotein nanoclusters. Eur. Biophys. J. 45:405-412. https://doi.org/10.1007/s00249 -015-1109-7.

Lin, M.-J., M. J. Lewis, and A. S. Grandison. 2006. Measurement of ionic calcium in milk. Int. J. Dairy Technol. 59:192-199. https:// doi.org/10.1111/j.1471-0307.2006.00263.x.

Luo, M., J. Xiao, S. Sun, F. Cui, G. Liu, W. Li, Y. Li, and Y. Cao. 2020. Deciphering calcium-binding behaviors of casein phosphopeptides by experimental approaches and molecular simulation. Food Funct. 11:5284-5292. https://doi.org/10.1039/d0fo00844c.

McCarron, D. A., and R. P. Heaney. 2004. Estimated healthcare savings associated with adequate dairy food intake. Am. J. Hypertens. 17:88-97. https://doi.org/10.1016/j.amjhyper.2003.08.008.

Mekmene, O., Y. Le Graët, and F. Gaucheron. 2009. A model for predicting salt equilibria in milk and mineral-enriched milks. Food Chem. 116:233-239. https://doi.org/10.1016/j.foodchem.2009.02 .039 .

Omoarukhe, E. D., N. Onnom, A. S. Grandison, and M. J. Lewis. 2010. Effects of different calcium salts on properties of milk related to heat stability. Int. J. Dairy Technol. 63:504-511. https://doi .org/10.1111/j.1471-0307.2010.00613.x.

On-Nom, N., A. S. Grandison, and M. J. Lewis. 2010. Measurement of ionic calcium, $\mathrm{pH}$, and soluble divalent cations in milk at high temperature. J. Dairy Sci. 93:515-523. https://doi.org/10.3168/ jds.2009-2634.

Ono, T., T. Ohotawa, and Y. Takagi. 1994. Complexes of casein phosphopeptide and calcium phosphate prepared from casein micelles by tryptic digestion. Biosci. Biotechnol. Biochem. 58:1376-1380. https://doi.org/10.1271/bbb.58.1376.

Ormrod, I. H. L., C. Holt, and P. C. Thomas. 1982. The inorganic constituents of milk IV. Diffusible calcium and magnesium concentrations in goat's milk and the effect of starvation. J. Dairy Res. 49:179-186. https://doi.org/10.1017/s0022029900022287.

Perego, S., E. Del Favero, P. De Luca, F. Dal Piaz, A. Fiorilli, L. Cantu, and A. Ferraretto. 2015. Calcium bioaccessibility and uptake by human intestinal like cells following in vitro digestion of casein phosphopeptide-calcium aggregates. Food Funct. 6:1796-1807. https://doi.org/10.1039/C4FO00672K.

Philippe, M., F. Gaucheron, Y. Le Graet, F. Michel, and A. Garem. 2003. Physicochemical characterization of calcium-supplemented skim milk. Lait 83:45-59. https://doi.org/10.1051/lait:2002049.

Ranjan, P., S. Arora, G. S. Sharma, J. S. Sindhu, V. K. Kansal, and R. B. Sangwan. 2005. Bioavailability of calcium and physiocochemical properties of calcium-fortified buffalo milk. Int. J. Dairy Technol. 58:185-189. https://doi.org/10.1111/j.1471-0307.2005.00208.x.

Sievanen, K., T. Huppertz, A. L. Kelly, and P. F. Fox. 2008. Influence of added calcium chloride on the heat stability of unconcentrated and concentrated bovine milk. Int. J. Dairy Technol. 61:151-155. https://doi.org/10.1111/j.1471-0307.2008.00391.x. 
Singh, A., S. Arora, G. S. Sharma, J. S. Sindhu, V. K. Kansal, and R. B. Sangwan. 2007. Heat stability and calcium bioavailability of calcium-fortified milk. Lebensm. Wiss. Technol. 40:625-631. https: //doi.org/10.1016/j.lwt.2006.03.009.

Singh, G., and K. Muthukumarappan. 2008. Influence of calcium fortification on sensory, physical and rheological characteristics of fruit yogurt. LWT 41:1145-1152. https://doi.org/10.1016/j.lwt.2007.08 .027 .

Tsioulpas, A., A. Koliandris, A. S. Grandison, and M. J. Lewis. 2010. Effects of stabiliser addition and in-container sterilisation on selected properties of milk related to casein micelle stability. Food Chem. 122:1027-1034. https://doi.org/10.1016/j.foodchem.2010 .03 .063 .

Van Kemenade, M. J. J. M., and P. L. de Bruyn. 1989a. The influence of casein on the kinetics of hydroxyapatite precipitation. J. Colloid Interface Sci. 129:1-14. https://doi.org/10.1016/0021 -9797(89)90411-6.

Van Kemenade, M. J. J. M., and P. L. De Bruyn. 1989b. The influence of casein on the precipitation of brushite and octacalcium phosphate. Colloids Surf. 36:359-368. https://doi.org/10.1016/ 0166-6622(89)80250-1.

Vavrusova, M., R. Liang, and L. H. Skibsted. 2014. Thermodynamics of dissolution of calcium hydroxycarboxylates in water. J. Agric. Food Chem. 62:5675-5681. https://doi.org/10.1021/jf501453c.
Vavrusova, M., and L. H. Skibsted. 2014. Calcium nutrition. Bioavailability and fortification. Lebensm. Wiss. Technol. 59:1198-1204. https://doi.org/10.1016/j.lwt.2014.04.034.

Wang, L., and G. H. Nancollas. 2008. Calcium orthophosphates: Crystallization and dissolution. Chem. Rev. 108:4628-4669. https://doi .org/10.1021/cr0782574.

Wang, L., and G. H. Nancollas. 2009. Pathways to biomineralization and biodemineralization of calcium phosphates: The thermodynamic and kinetic controls. Dalton Trans. 2665-2672. https://doi .org/10.1039/b815887h.

White, J. C. D., and D. T. Davies. 1963. The determination of citric acid in milk and milk sera. J. Dairy Res. 30:171-189. https://doi .org/10.1017/S0022029900011353.

\section{ORCIDS}

Qian Wang @ https://orcid.org/0000-0002-1128-2520

Carl Holt @ https://orcid.org/0000-0002-2087-1546

Tommy Nylander (1) https://orcid.org/0000-0001-9420-2217

Ying Ma @ https://orcid.org/0000-0002-2641-7926 